\title{
Editorial
}

\section{The Maturity of Brazilian Dental Journals}

To reach maturity, one should not only behave like an adult, but should expose himself to a mature and adult environment. That is what we did during the $2^{\text {nd }}$ International Meeting of Scientific Editors in the Dental Field, which was held in Bauru, SP, last November. Editors from some of the most representative international and Brazilian dental journals gathered in a joint effort to improve the quality of published dental science in the world. We trust that all participants could realize the importance of the meeting for the future of our journals. We dare to say that we gave a large step towards maturity and improvements in our publishing quality. We, the Editors and Coordinators of the meeting would like to express our gratitude to all guest speakers, participants and to Bauru School of Dentistry for making it possible. We see you all at the $3^{\text {rd }}$ meeting.

Beginning on next year, Dr. José M. Granjeiro will leave Bauru to assume a new life and position at the Fluminense Federal University (UFF) in Rio de Janeiro. While he will still contribute to the journal as an Associate Editor, Dr. Ricardo M. Carvalho will take up the job as the new Editor. The continuity of the work for improvements is warranted, and will come along with new changes in the Editorial Board. Within a short time, new Associate Editors will be invited to join the journal. They will be selected according to their specific area of expertise and will be responsible to improve the preliminary screening of manuscripts, expedite revision process, and suggest the Editor the final recommendation of the manuscripts.

This issue brings a fine revision on the microbiological basis for periodontal therapy (Feres et al.). Authors are Brazilian researchers who had been working in collaboration with the Forsyth Institute in Boston, USA, which is one of the pinnacles of periodontal research in the world. Current periodontal research is certainly the most medical-related topic in Dentistry. Readers will have the opportunity to get acquainted with the latest developments and findings on the issue of periodontal therapy.

We take the opportunity to acknowledge all the members of the Editorial Board, ad-hoc reviewers, contributors and our staff for this very positive year for JAOS. With your continuous confidence in the journal, we foresee an even better coming year.

We wish you all the very best for the Holiday Season and hope to see you in these pages next year.

\section{The Editors}

